\title{
Study on Determination of Contents of the Main Components of Tea Polyphenols
}

\author{
Mao Luo and Hua Peng
}

\begin{abstract}
Objective: To establish the determination of the total sugar, fat, starch, protein and caffeine of tea polyphenols. Method: Total sugar were measured using Anthrone Colorimetry, the fat and starch were determined with acid hydrolysis method, determination of protein by digestion and alkalization distillation, and HPLC was applied to determination of the caffeine(CAF). Separation was performed on $\mathrm{C} 18$ column $(4.6 \mathrm{~mm} \times 250 \mathrm{~mm}$ ' $5 \mu \mathrm{m})$ with the mobile phase consisting of water - methanol $(7: 3)$. Flow rate of the mobile phase was set at $1.8 \mathrm{ml} / \mathrm{min}$ and UV-detection at $280 \mathrm{~nm}$. The temperature of column was set at $40^{\circ} \mathrm{C}$ and sample injection volume was $30 \mu \mathrm{l}$. Result: The total sugar content reached to $26.93 \mathrm{mg} / \mathrm{g}-80.61 \mathrm{mg} / \mathrm{g}$, fat content reached $8.8 \mathrm{mg} / \mathrm{g}$ to 14.36 $\mathrm{mg} / \mathrm{g}$, starch content reached $0.27 \mathrm{mg} / \mathrm{g}$ to $2 \mathrm{mg} / \mathrm{g}$, protein content reached $47.64 \mathrm{mg} / \mathrm{g}$ to $89.83 \mathrm{mg} / \mathrm{g}$, and the liner range of caffeine content varied from $2.7 \mathrm{mg} / \mathrm{g}$ to $22.5 \mathrm{mg} / \mathrm{g}(r=0.997)$, average recovery was $96.78 \%, R S D=0.15 \%(n=5)$. Conclusion: Combined with Anthrone Colorimetry, acid hydrolysis method, digestion and alkalization distillation, it is effective in determination of components in tea polyphenols. Result indicated that HPLC is simple accurate, reliable and reproducible, so it can be used to identification and determination of the caffeine content in tea polyphenols. The chromatographic system is stable and applicable.
\end{abstract}

Index Terms-Tea polyphenols, total sugar, fat, starch, protein, caffeine, HPLC.

\section{INTRODUCTION}

Tea polyphenol (TF for short), also called tea tannin, tea tannic acid, or tea tannins, is polyhydroxyphenol compounds extracted from the tea, which is the key material in determining the tea quality. Large quantities of researches show that tea polyphenol has broad-spectrum and specific curative effects in antioxidation, anti-atherosclerosis, resistance to dental caries, antitumor, anti-radiation, anti-aging, antimicrobial and in reducing blood pressure, hematic fat, and blood sugar, and even in anti-HIV [1]-[5].

The determination research on all characteristic ingredients of tea polyphenol has been reported, but such research has not been reported systematically, which aims to establish a content determination method, combined with poly-determination methods, to determine the main contents in tea polyphenol systematically and accurately.

Manuscript received July 22, 2012; revised October 26, 2012. Support by the Foundation of Department of Education of Sichuan Province (11ZB123) and Foundation of Luzhou Medical College.

Mao Luo is with the Research Center for Drug Discovery, Luzhou Medical College, Luzhou 646000, China (e-mail: luomao20050908@ yahoo. $\mathrm{cn})$.

Hua Peng is with the Sichuan Tourism University, Chengdu 610071, China (e-mail: 16828333@qq.com).
This paper carried out the separation quantitative analysis on the contents of total sugar, starch, fat, protein and caffeine in the tea polyphenol using anthrone colorimetry, acid hydrolysis, digestion, alkalize distillation method and HPLC method, and founded the content determination method of measuring the main contents in tea polyphenol systematically to be used in the quality control in tea polyphenol and concerning products.

\section{EXPERIMENTAL SECTION}

\section{A. Apparatus and Reagent}

Agilent 1100 high performance liquid chromatograph (Agilent America), ultraviolet and visible spectrophotometer type 752 (Pgeneral Shanghai), electric-heated thermostatic water bath (Jinghong Shanghai), electronic constant temperature drying oven (Yuejin Shanghai), Biofuge high speed tabletop centrifuge (Thermo Germany), microfiltration membrane (Xunwei Shanghai), desktop NC ultrasonic cleaning machine KQ-500DE (Anduo Nanjing), control temperature adjust electric heating set (Xiandai Shandong), trace nitrogen distiller (Xihuayi Beijing), rotary evaporator RE-52 (Yarong Shanghai), precision acidity meter PHSJ-3F (Leici Shanghai), electronic balance (Sartorius Germany).

Standard glucose (Zhongxi Great Science and Technology), methanol and acetonitrile (chromatographically pure, Tianjin Starbucks Science and Technology), Caffeine (99\%) (HPLC, A Johnson Matthey Company), other reagents (Chengdu Xingchi Chemical), tri-distilled water (homemade). Tea polyphenol is provided by Sichuan Agricultural University (five batches; raw material tea is produced in Sichuan Yaanmeng mountain); $5 \mathrm{ml}$ : tea polyphenol extract $100 \mathrm{mg}$; labeled respectively as: sample 1, sample 2, sample 3, sample 4, and sample 5.

\section{B. To Test the Total Sugar Content in Tea Polyphenol Using Anthrone Colorimetry}

\section{1) The drawing of standard curve}

Take seven dry clean tubes and number them; then add standard glucose, tri-distilled water, anthrone reagent in turn into the tubes and put them in boiling water for 10 minutes. After that, move them quickly into icy water to cool down, then put them in the dark for 10 minutes to test the absorbance in wave length of $620 \mathrm{~nm}$. Draw a coordinate graph with absorbance for ordinate and standard solution concentration $(\mathrm{mg} / \mathrm{ml})$ for $\mathrm{x}$-coordinate.

\section{2) Preprocessing of the samples}

Weigh accurately each sample for $0.5 \mathrm{~g}$, and put them into a $50 \mathrm{ml}$ conical flask; then add $20 \mathrm{ml}$ tri-distilled water to 
dissolve them followed by adding $10 \mathrm{ml}$ solution of lead subacetate, and shake well till light yellow precipitation appears, then put them still for 10 minutes; add $10 \mathrm{ml}$ solution of sodium sulfate and shake well; at last, centrifuge them in $1000 \mathrm{r} / \mathrm{min}$ for 15 minutes, then take the upper clear liquid to make $100 \mathrm{ml}$ solution for reserve.

\section{3) Content determination and calculation}

Get all the samples got from preprocessing, and each sample needs three parallel experiments of which each parallel experiment needs three repetitions. Take nine dry clean tubes and number them; then add sample solution, tri-distilled water, anthrone reagent in turn into the tubes and put them in boiling water for 10 minutes. After that, move them quickly into icy water to cool down, then put them in the dark for 10 minutes to test the absorbance in wave length of $620 \mathrm{~nm}$. According to the formula ( $w$ : sugar mass fraction $(\%)$; $C$ : sugar mass fraction from standard curve $(\mathrm{mg} / \mathrm{ml}) ; V$ : the sample's volume after dilution ( $\mathrm{ml}) ; m$ : the sample quality $(\mathrm{mg})$ ), calculate the sugar content in each sample.

$$
w=\frac{c \times v}{m} \times 100 \%
$$

\section{To Determine the Fat Content in Tea Polyphenol Using Acid Hydrolysis}

\section{1) The determination of contents}

Weigh accurately each sample for $1.0 \mathrm{~g}$, and put them into a $50 \mathrm{ml}$ conical flask with adding water $8 \mathrm{ml}$ and hydrochloric acid $10 \mathrm{ml}$; then put the conical flask into $75^{\circ} \mathrm{C}$ water for 90 minutes with mixing them every 5 minutes till the sample completely dissolves. Put in ethanol (95\%) 10ml, and after the sample cools down, transfer it into the separatory funnel; take ether $25 \mathrm{ml}$ to wash the conical flask in times, then transfer it into the separatory funnel followed by shaking out with plug for 1 minutes. Put it still without the plug for 12 minutes, then add $10 \mathrm{ml}$ mixture of ether and equivalent petroleum ether to wash the fat sticked on the bottle stopper and surrounding place; put it still for 20 minutes after shaking it out with the plug. Skim the liquid after it becomes different layers by letting the lower layer of liquid out from the funnel mouth and suck out the upper layer of liquid. Put upper layer of liquid into constant-weight conical flask and lower layer of liquid into separatory funnel for skimming with sucking up upper layer into constant-weight conical flask. Put the conical flask into $60^{\circ} \mathrm{C}$ water to dry it, and then bake it 2 hours in $100^{\circ} \mathrm{C}$ oven followed by putting it in the dryer for 30 minutes; then weigh it and record the data. Repeat the above steps until the conical flask keeps constant weight.

2) Calculation formula

$$
x=\frac{m_{1}-m_{0}}{m_{2}} \times 100
$$

(X: fat content in the sample $(\%)$; ml: conical flask and the fat quality $(\mathrm{g}) ; \mathrm{m} 0$ : the conical flask's quality $(\mathrm{g}) ; m 2$ : the sample's quality $(\mathrm{g}))$.

\section{To Determine the Starch Content in Tea Polyphenol Using Acid Hydrolysis}

\section{1) To process the sample}

Weigh accurately each sample for $2.0 \mathrm{~g}$, and repeat twice; put them in dry clean Petri dishes which are next put into drying oven. Wash and clean the fat in the sample with $30 \mathrm{ml}$ ether; wait till the ether fully volatilizes, then wash it with $150 \mathrm{ml}$ ethanol to remove the reducing sugar.

\section{2) To produce the sample solution}

Take $100 \mathrm{ml}$ tri-distilled water to wash the residue from last step into a $250 \mathrm{ml}$ conical flask; joint it to condenser pipe after adding $30 \mathrm{ml}$ hydrochloric acid into it and put it in boiling water for reflux for 2 hours; when it cools down, add 2 drops of methyl red and drip with $\mathrm{NaOH}$ to adjust the $\mathrm{PH}$ as 7. Shake it out and put it still for 10 minutes after adding 20 $\mathrm{ml}$ lead acetate $(200 \mathrm{~g} / \mathrm{l})$; then put in $20 \mathrm{ml}$ sodium sulfate $(100 \mathrm{~g} / \mathrm{l})$ to remove excess lead; get $500 \mathrm{ml}$ liquid out of it and the upper clear solution from centrifugal is the sample solution.

\section{3) To determine the sample solution}

The calibration of alkaline tartaric acid copper solution: set 3 parallel experiments by taking alkaline tartaric acid copper solution A $5 \mathrm{ml}$ and solution B $5 \mathrm{ml}$ into a $150 \mathrm{ml}$ conical flask, and add tri-distilled water $10 \mathrm{ml}$ and 2 grains of glass beads. Add glucose standard solution $9 \mathrm{ml}$ into an acid burette, and heat the conical flask until it boils for 2 minutes, then drop the glucose standard solution with a speed of $2 \mathrm{~s} / \mathrm{d}$ until the blue color of the solution fades away; write down the total volume of the standard solution by consumption. The prediction of the test sample solution: take each sample solution for $10 \mathrm{ml}$ respectively, and put alkaline tartaric acid copper solution A $5 \mathrm{ml}$ and solution B $5 \mathrm{ml}$ into a $150 \mathrm{ml}$ conical flask; drip the glucose standard solution just until the blue color fades away and write down glucose volume by consumption; the formula for predicting the volume is (V1: the glucose volume by consumption in dripping; $V 2$ : the volume of glucose by consumption in prediction). The determination of test sample solution: set two parallel experiments for each sample; add alkaline tartaric acid copper solution A $5.0 \mathrm{ml}$ and solution B $5.0 \mathrm{ml}$ each time, and tri-distilled water $10 \mathrm{ml}$; heat it until it boils; continue to drop sample solution while it is still hot until the blue color just fades away; write down the volume of sample solution by consumption.

$$
V=\frac{(V 1-V 2)}{10} \times \frac{V 2}{V 1}
$$

\section{E. Determine the Protein Content in Tea Polyphenol Using Slaking and Alkalization Distillation}

\section{1) The slaking of the sample}

First set the concentration of sulfuric acid standard solution; weigh respectively the sample for $0.5 \mathrm{~g}$, and put it into a dry $250 \mathrm{ml}$ nitrogen bottle; add copper sulfate $0.1 \mathrm{~g}$, potassium sulfate $1.0 \mathrm{~g}$ and sulfuric acid $10 \mathrm{ml}$, then shake well followed by heating it on an electric stove; the solution appears reddish brown after 2 hours and appears transparent blue-green after 3 hours; continue heating for 0.5 hour, then cool it down and add tri-distilled water $20 \mathrm{ml}$; make it to be $100 \mathrm{ml}$ solution. Set three parallel experiments and blank control for each sample.

\section{2) The alkalization distillation of the sample}

Install the nitrogen device, add water to two-thirds place of 
the water vapor reaction bottle; put in methyl red $5 \mathrm{ml}$ and sulfuric acid $5 \mathrm{ml}$; heat it and wash the reaction device with boiling water. After the washing, put sample solution $10 \mathrm{ml}$ (or blank liquid) into the reaction tube and insert the ground stopper; add $2 \%$ boric acid $25 \mathrm{ml}$ into a $250 \mathrm{ml}$ conical flask, and put it to the bottom of the condenser pipe; add $20 \%$ $\mathrm{NaOH}$ solution $20 \mathrm{ml}$ into the reaction tube from the mouth for adding sample to make the sample solution in the reaction tube form black precipitation or become dark blue; then wash the mouth with tri-distilled water, insert the ground stopper, and seal the mouth with some water. Retain the vapour in the reaction tube for 10 minutes of distillation, lift the bottom of the condenser pipe off the absorption liquid surface, and distillate for one minute; use naphthalene's reagent to test it, and if there's no ammonia, then stop undertaking distillation liquid and discharge the waste liquor; wash the device.

\section{3) Titration and calculating the outcomes}

Accurately suck up $10 \mathrm{ml}$ sample slaking solution into the reaction chamber; move the conical flask after 9 minutes' distillation, and after another 4 minutes distillation, the color of boric solution changes from colorless to green; another 5 minutes distillation, move the conical flask and make the liquid away from the bottom of condenser pipe; another 1 minute of distillation, wash the outside of the condenser's bottom with some water. Take the conical flask and titrate it to colorless with sulfuric acid standard titration solution. Mark the consumed volume of sulfate as $V 1$, the volume of sulfate consumed by blank slaking solution as $V 2$, and test each sample slaking solution 3 times. Here's the formula: $(C$ : concentration of sulfuric acid standard solution mol/L; $V 1$ : the volume of sulfuric acid standard solution consumed by titrating the sample absorption solution $\mathrm{ml} ; \mathrm{V} 2$ : the volume of sulfuric acid standard solution consumed by titrating the sample blank solution $\mathrm{ml} ; \mathrm{m}$ : the quality of tea polyphenol $(\mathrm{g})$; $F$ : the conversion coefficient of protein content in tea polyphenol 6.25).

$$
\operatorname{Pr} \text { otein } \%=\frac{C \times(V 1-V 2) \times 0.01401}{m \times \frac{10}{100}} \times F \times 100
$$

\section{F. To Determine the Caffeine Content in Tea Polyphenol Using HPLC}

\section{1) Chromatographic condition}

Detect the wavelength: chromatographic column $(4.6 \mathrm{~mm}$ $\times 250 \mathrm{~mm}, 5 \mu \mathrm{m}$ ); ultraviolet detection wavelength of $280 \mathrm{~nm}$; mobile phase: water-methanol (7:3); velocity: $1.8 \mathrm{ml} / \mathrm{min}$; column temperature: $40^{\circ} \mathrm{C}$; sample quantity: 30ul;

2) Weigh caffeine (purity: not less than 99\%) 10mg, dissolve it with methanol

Water (1:4), and make it a constant volume of $10 \mathrm{ml}$; after the standard solution cools to the room temperature, take $4 \mathrm{ml}$ of it and make a constant volume of $100 \mathrm{ml}$ with water as the mother solution (containing caffeine $0.05 \mathrm{mg} / \mathrm{ml}$ ). Dilute it respectively to caffeine standard solution of $0.005 \mathrm{mg} / \mathrm{ml}$, $0.01 \mathrm{mg} / \mathrm{ml}, 0.015 \mathrm{mg} / \mathrm{ml}, 0.02 \mathrm{mg} / \mathrm{ml}, 0.025 \mathrm{mg} / \mathrm{ml}, 0.03$ $\mathrm{mg} / \mathrm{ml}, 0.035 \mathrm{mg} / \mathrm{ml}$, and $0.04 \mathrm{mg} / \mathrm{ml}$, then determine and draw the caffeine standard curve.

\section{3) The production of samples}

Repeat three times; weigh respectively tea polyphenol sample (number 1 to number 5) $10 \mathrm{~g}$ with constant weight, dissolve them with $2-3 \mathrm{ml}$ boiling water above $90^{\circ} \mathrm{C}$; cool it down, and transfer it into a $10 \mathrm{ml}$ volumetric flask by constant volume; filter it through $0.45 \mu \mathrm{m}$ film; abandon the initial 2 $\mathrm{ml}$ filtrate, and the rest filtrate is test solution.

\section{4) Calculation of the outcomes}

The mass fraction $(W)$ of caffeine is calculated in its dry state $(\%)$, and here's the formula: $(C 1$ : the caffeine content in the determination solution $(\mathrm{ug} / \mathrm{ml}) ; V 1$ : the total volume of the sample $(\mathrm{ml}) ; V 2$ : consumed sample's volume $(\mu \mathrm{l}) ; m$ : sample quality $(\mathrm{g}) ; C 2$ : the content of dry materials in the sample (\%)).

$$
R S D=\sqrt{\frac{\sum_{i=1}^{6}\left(x_{i}-\overline{x_{2}}\right)^{2}}{n-1}}
$$

\section{OUTCOMES AND DISCUSSION}

\section{A. To Determine the Caffeine Content in Tea Polyphenol by Using HPLC}

\section{1) Drawing the standard curve $D$}

Raw the standard curve (Fig. 1) with concentration gradient as abscissa and peak area as ordinate, and get the regression equation: $Y=29875 X+22.3, R^{2}=0.9969$, and the chromatogram of caffeine standard curve is shown as Fig. 2.

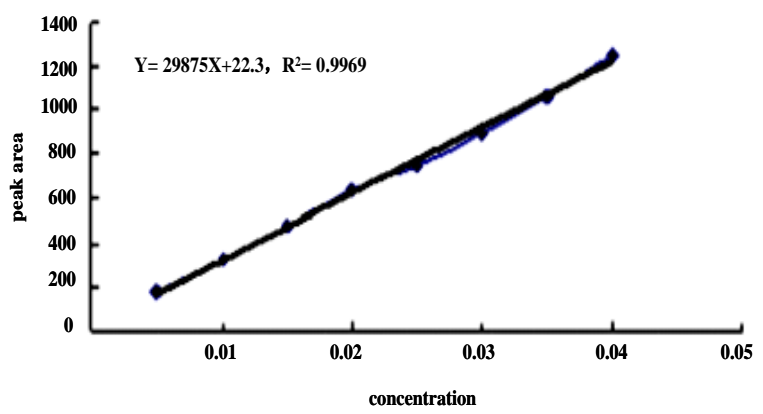

Fig. 1. The calibration curve for caffeine.

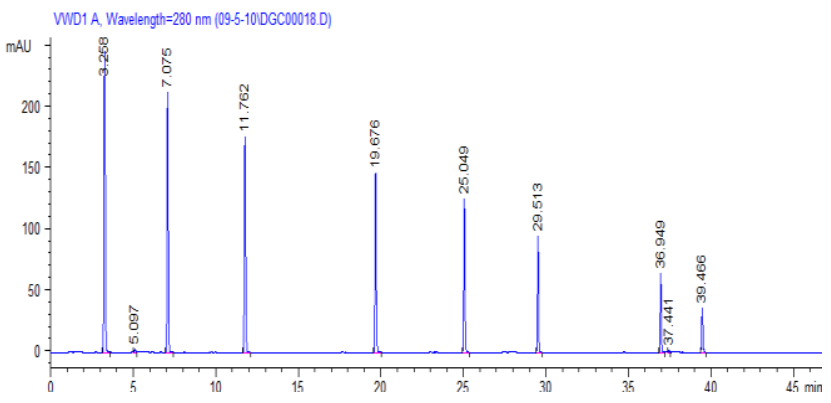

Fig. 2. HPLC chromatograms of the calibration curve for caffeine.

\section{2) The ccuraacy test and reproducible t-test}

Take dry caffeine standard solution $0.015 \mathrm{mg} / \mathrm{ml}$ for successive six times; chromatographic condition: detect the wavelength: chromatographic column C18 (4.6 mm $\times 250$ $\mathrm{mm}, 5 \mu \mathrm{m})$; ultraviolet detection wavelength of $280 \mathrm{~nm}$; mobile phase: water-methanol (7:3); velocity: $1.8 \mathrm{ml} / \mathrm{min}$; column temperature: $40^{\circ} \mathrm{C}$; consumed sample quantity: $30 \mu \mathrm{l}$. According to the peak-height formula. 


$$
R S D=\sqrt{\frac{\sum_{i=1}^{6}\left(x_{i}-\overline{x_{2}}\right)^{2}}{n-1}}
$$

We get that $R S D=1.09 \%$; this proves that chromatographic condition is reasonable in this experimental condition. Take again sample number 1 to number 5 , and weigh them precisely; produce respectively test solution, and carry out the determination; according to the above chromatographic condition, we can get $R S D=2.291 .94 \%$ by peak-height formula. The outcome shows that the experiment method is reliable and has a good reproducibility.

\section{3) Test on recovery rate}

Add standard solution $0.015 \mathrm{mg} / \mathrm{ml}$ to sample number 1 to number 5 that the content is known; mix them well, and filter it with $0.22 \mu \mathrm{m}$ microporous filter head; consumed sample quantity: 30ul; the determination outcomes of each group is: the average recovery rate is $96.78 \%, R S D=0.15 \% \quad(n=6)$ (Table I).

TABLE I: RECOVERY TEST

\begin{tabular}{cccccc}
\hline CAF & $\begin{array}{c}\text { Reference } \\
\text { Substance }\end{array}$ & $\begin{array}{c}\text { Measured } \\
\text { Quantity }\end{array}$ & $\begin{array}{c}\text { Recovery } \\
\text { Quantity }\end{array}$ & $\begin{array}{c}\text { Recove } \\
\text { ry Rate }\end{array}$ & RSD\% \\
\hline $\mathbf{m g}$ & $\mathbf{m g}$ & $\mathbf{m g}$ & $\mathbf{m g}$ & $\mathbf{\%}$ & $\%$ \\
0.0026 & 0.0075 & 0.0109 & 0.0083 & $110 \%$ & \\
0.0105 & 0.0075 & 0.0185 & 0.0079 & $106 \%$ & \\
0.0085 & 0.0075 & 0.1435 & 0.0059 & $78 \%$ & $0.15 \%$ \\
0.0055 & 0.0075 & 0.0143 & 0.0089 & $118 \%$ & \\
0.0027 & 0.0075 & 0.0096 & 0.0062 & $82 \%$ & \\
0.0037 & 0.0075 & 0.0102 & 0.0065 & $86.7 \%$ & \\
\hline
\end{tabular}

\section{4) Determination of contents in sample}

Make 3 parallel of sample solution of sample number 1 to number 5; according to the above chromatographic condition, the consumed sample quantity is $30 \mathrm{ul}$; calculate the caffeine concentration of each sample according to each group of peak area, the caffeine content of the 5 groups of samples are $2.7 \mathrm{mg} / \mathrm{g}-22.5 \mathrm{mg} / \mathrm{g}$, and the chromatogram of the caffeine content of each sample is shown in Fig. 3 to Fig. 7.

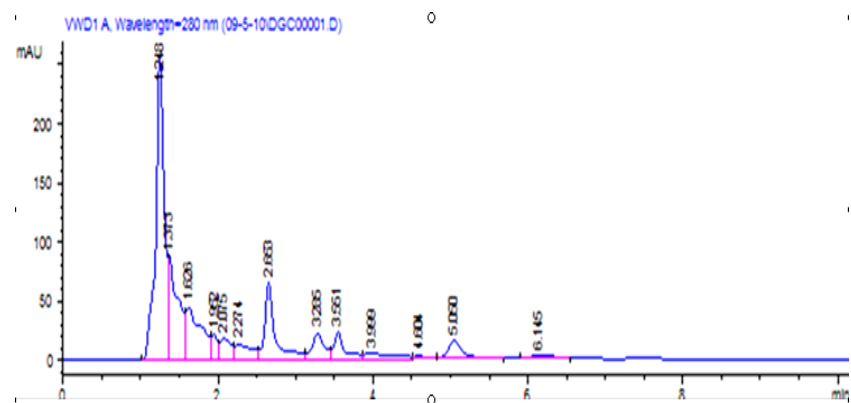

Fig. 3. HPLC chromatograms of sample 1 for caffeine.

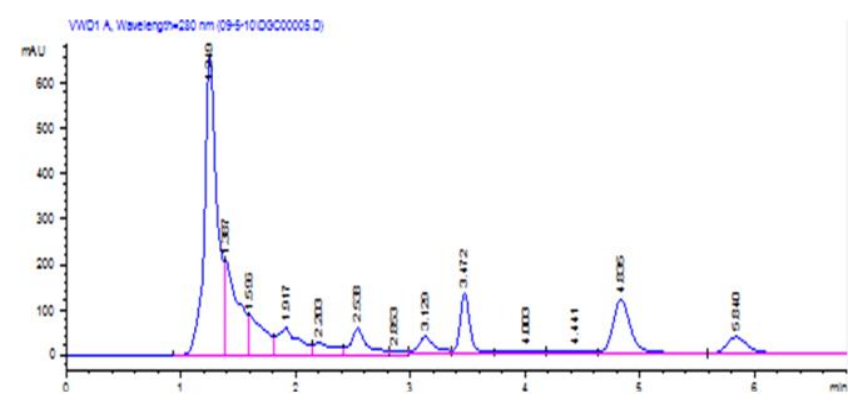

Fig. 4. HPLC chromatograms of sample 2 for caffeine.

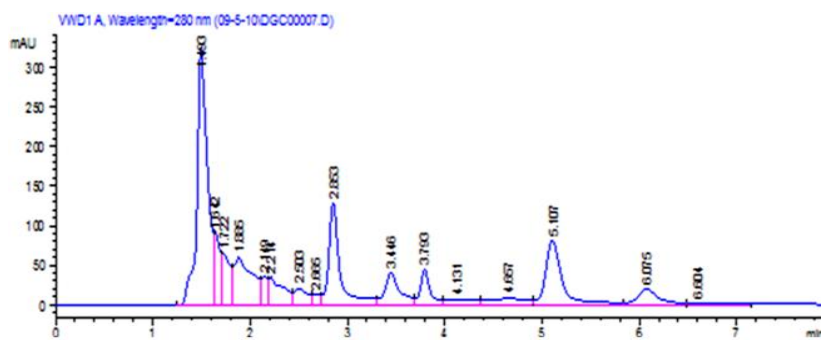

Fig. 5. HPLC chromatograms of sample 3 for caffeine.

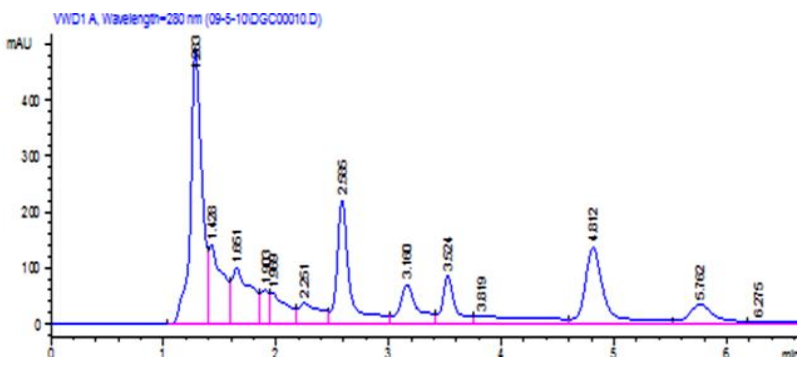

Fig. 6. HPLC chromatograms of sample 4 for caffeine.

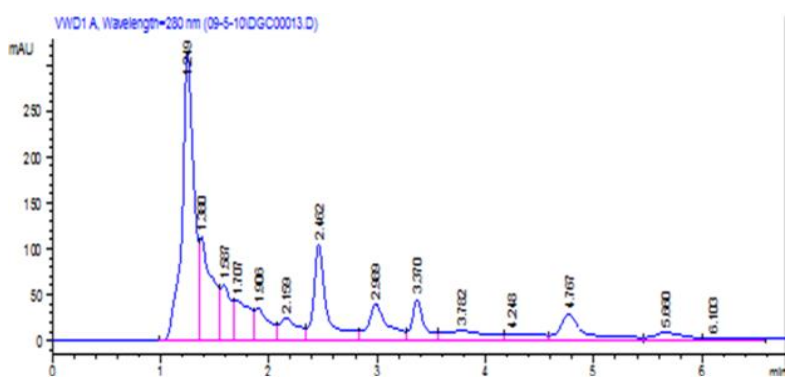

Fig. 7. HPLC chromatograms of sample 5 for caffeine.

\section{B. The Content of the Main Elements in Five Batched of Tea Polyphenol Samples}

We can carry out the effective quantitative determination on the total sugar, starch, fat, protein in tea polyphenol using combination of anthrone colorimetry (Fig. 8), acid hydrolysis, slaking and alkalization distillation. And here's the outcome(Table II, Fig. 9), in the five batches of tea polyphenol samples, total sugar content $26.93 \mathrm{mg} / \mathrm{g}$ to 80.61 $\mathrm{mg} / \mathrm{g}$; fat content $8.8 \mathrm{mg} / \mathrm{g}$ to $14.36 \mathrm{mg} / \mathrm{g}$; starch content 0.27 $\mathrm{mg} / \mathrm{g}$ to $2 \mathrm{mg} / \mathrm{g}$; protein content $47.64 \mathrm{mg} / \mathrm{g}$ to $89.83 \mathrm{mg} / \mathrm{g}$; caffeine content $2.7 \mathrm{mg} / \mathrm{g}$ to $22.5 \mathrm{mg} / \mathrm{g}$; the linear relation is good in its limits $(r=0.997, n=6)$, and the average recovery rate is $96.78 \%$, and RSD is $0.15 \%$; among them, the starch content in sample number 5 is the highest, and higher than other samples significantly; the fat, protein and caffeine contents in sample number 2 are respectively the highest, and higher than other samples significantly.

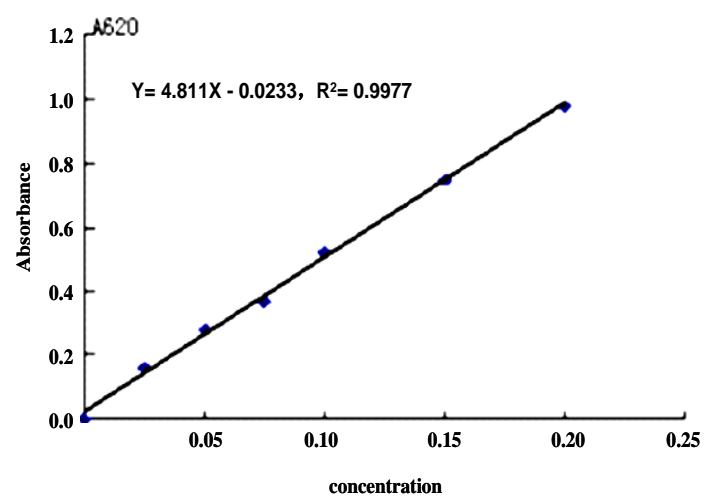

Fig. 8. Anthrone colorimetric total sugar - the standard curve produced. 


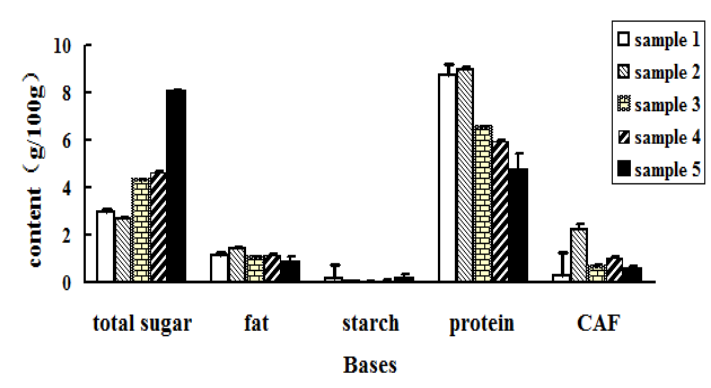

Fig. 9. Analysis and comparison of five major polyphenol components in sample (1-5).

TABLE II: FiVE MAJOR POLYPHENOL COMPONENTS IN SAMPLE(1-5).

\begin{tabular}{cccccc}
\hline \multirow{2}{*}{ Sample } & $\begin{array}{c}\text { Total } \\
\text { Sugar }\end{array}$ & Fat & Starch & Protein & CAF \\
\hline \multirow{2}{*}{1} & 2.945 & 1.15 & 0.1565 & 8.769 & 0.27 \\
& \pm 0.141 & $\pm 0.03^{*}$ & $\pm 0.013^{*}$ & $\pm 0.056^{*}$ & \pm 0.040 \\
2 & 2.693 & 1.436 & 0.0313 & 8.983 & 2.25 \\
& \pm 0.089 & $\pm 0.04^{*} *$ & \pm 0.001 & $\pm 0.058^{* *}$ & $\pm 0.179^{*}$ \\
3 & 4.349 & 1.113 & 0.0270 & 6.553 & 0.70 \\
& $\pm 0.559^{*}$ & $\pm 0.05^{*}$ & \pm 0.006 & \pm 0.088 & \pm 0.130 \\
4 & 4.632 & 1.14 & 0.0277 & 5.948 & 1.03 \\
& $\pm 0.411^{*}$ & $\pm 0.13^{*}$ & \pm 0.005 & \pm 0.055 & $\pm 0.677^{*}$ \\
5 & 8.061 & 0.88 & 0.2000 & 4.764 & 0.60 \\
& $\pm 0.969^{* *}$ & \pm 0.21 & $\pm 0.035^{* *}$ & \pm 0.067 & \pm 0.068 \\
\hline
\end{tabular}

\section{THE CONCLUSION}

Tea polyphenol, as a new natural antioxidant and a biological regulator on functions, is gradually becoming a hot research issue on multifunctional additive and health products all over the world [6]-[7]. China's researches on tea polyphenol have been in the lead position in the world. Tea polyphenol as natural antioxidant is one of the food additives in our country. Considering the multifunctional effects on health care of tea polyphenol, it is very important to further study the contents of the main elements in tea polyphenol from tea [8]. At present, it has been reported on the determination research of all the characteristic elements in tea polyphenol. But it has no systemic report on the research of establishing systemic and accurate methods determining the contents of the main elements in tea polyphenol, combined with multiple determination methods. This paper conducts the separation analysis on the content of total sugar, starch, fat, protein and caffeine in tea polyphenol using a combination of anthrone colorimetry, acid hydrolysis, slaking and alkalization distillation, and HPLC; and establishes systemic method determining the content of the main elements in tea polyphenol used for the quality control of tea polyphenol and the concerning products, which possesses the advantages of simple processing, short analysis cycle, good reproducibility and reliability and practical use etc.

This paper established the optimal chromatographic condition of determining the content of caffeine in tea polyphenol from tea using HPLC. W. X. Yan [9] and Z. Ji [10] employed high performance liquid chromatography to determine the caffeine in tea polyphenol. And according to the set mobile phase, this paper repeats this method and the outcome shows that the standard peak appears bifurcation phenomenon in the peak, which has effects on the outcome. The outcome of using the established chromatographic condition in this paper to determine the content of caffeine shows that the peak appears faster and the standard peak shape is more optimal. It turns out that our method is more reliable and practical and can give an accurate quantifying and evaluation in the content of caffeine in tea polyphenol.

\section{REFERENCES}

[1] Y. Hara and M. Honda, "The inhibition of $\alpha$-amylase by tea polyphenols," Agric Biol Chem, vol. 54, pp. 1939-1945, August 1990.

[2] K. Muramatsu, M. Fukuyo, and Y. Hara, "Effect of green tea catechins on plasma cholesterol level in cholesterol-fed rats," J. Nutr Sci Vitaminol, vol. 32, pp. 613-622, December 1986.

[3] K. Yoshino, I. Tomita, M. Sano, I. Oguni, Y. Hara, and M. Nakano, "Effects of long-term dietary supplement of tea polyphenols on lipid peroxide levels in rats," Age, vol. 17, pp. 79-85, July 1992.

[4] I. Oguni, K. Nasu, S. Kanaya, Y. Ota, S. Yamamoto, and T. Nomura, "Epidemiological and experimental studies on the antitumor activity by green tea extracts," Jpn. J. Nutr. vol. 47, pp. 93-102, March 1989.

[5] C. Rui, "Chemical Materials of Function Components of the Tea and its Application,” Journal of Anhui Agricultural Sciences, vol. 32, pp. 1031-1033, 1036, May 2004.

[6] Z. Xun, H. T. Jun, W. Yu, Z. Z. Hang, and L. Lan, "Study on fingerprint chromatograms of teapolyphenols by HPLC and LC - MS/MS," Chin J Pham Anal, vol. 27, pp. 389-394, May 2007.

[7] W. Dong and K. Jian, "The efficiency of tea polyphenol, extraction and the application prospect," Journal of Xinjiang University (Natural Science Edition), vol. 24, pp. 217-221, February 2007.

[8] C. J. Ying, G. J. Lin, and Z. C. Yan, "Research progress on polyphenols of tea," Chinese Traditional and Herbal Drugs, vol. 35, pp. 1011-1013, October 2004.

[9] J. E. DiNunzio, "Determination of caffeine in beverages by high performance liquid chromatography," Journal of Chemical Education, vol. 62, pp. 446, May 1985.

[10] Z. Ji, W. H. Ming, M. J. Yi,W. Li, and Z. B. Tang, "HPLC determination of tea polyphenols and caffeine in green tea," PTCA(Part B: Chem. Anal.), vol. 48, pp. 312-314, March 2012.

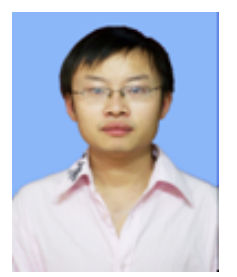

Mao Luo was born in Leshan of Sichuan province; Research Center for Drug Discovery of Luzhou Medical College; Assistant Research Fellow; Plant Breeding and Genetics of doctor, engage in research of drug and functional food research.

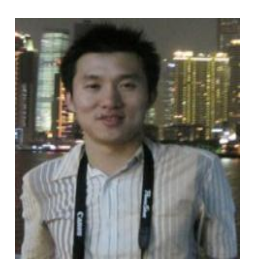

Hua Peng was born in Luzhou of Sichuan province; Sichuan Tourism University; Assistant Research Fellow; Plant Breeding and Genetics of master, engage in research of drug and functional food research. 